\title{
Development of Chemosorbent Based on Metallic Waste for Cleaning Mine Water from Molybdenum
}

\author{
Alexander Evgenyevich Isakov', Vera Anatolevna Matveeva', \\ Mariia Alexeevna Chukaeva ${ }^{1^{*}}$ \\ 1 Saint-Petersburg Mining University, $21^{\text {st }}$ line V.O., 2, 199106 Saint Petersburg, Russian Federation \\ * Corresponding author's e-mail: omnp@spmi.ru
}

\begin{abstract}
The article presents the results of hydrochemical studies of water objects, located in the impact zone of one of the largest mining enterprises in the Russian Federation - JSC "Apatite". According to the monitoring studies, the source of surface water pollution with molybdenum was determined, geochemical assessment of the molybdenum transformation in the system "ore-bearing rocks - mine water - surface water" was performed. In order to reduce the technogenic load on the surface water located in the considered area, the way of large-tonnage mine waters purification from molybdenum was proposed. The method involves using the chemical sorbent based on waste metals. The method of sewage purification will allow solving one of the key environmental problems of the considered enterprise and, in addition, to improve the environmental situation in the considered area as well as the quality of the local population life.
\end{abstract}

Keywords: molybdenum, leaching, mine waters, hydrochemical anomaly, the metal waste, the chemical adsorbent.

\section{INTRODUCTION}

A significant part of the Russian Federation deposits is currently being developed by means of an underground method that leads to the formation of large-tonnage mine runoff waters. The total volume of water diverted during mining operations reaches several cubic kilometers in the whole country. As a result of pumping out water, cones of depression with water downgrades are formed in the area over thousands of square kilometers. Thus, the lowering of the groundwater level reaches $50+113 \mathrm{~m}$ in the area of the Kursk magnetic anomaly, increasing with a speed of 1-3 meters per year. The cone of depression area is around $40 \mathrm{~km}^{2}$, and in the Donbass region 160 thousand $\mathrm{km}^{2}$.

Water sources and wells dry out due to the lowering of groundwater levels. However, mine waters have a variable chemical composition, which eliminates the possibility of using it for drinking purposes, but also impedes their use in production systems without time-consuming treatment. For this reason, mine waters, containing high amount of chemical elements and compounds, are still discharged into surface water bodies, which leads to the formation of hydrochemical areas and flows of pollution. Chronic pollution of water bodies entails a violation of water ecosystems, reducing the life quality of the population and the reduction of fresh water recourses on the Earth.

The purpose of this work was to study hydrochemical molybdenum contrast anomaly, located in the immediate vicinity of the world's largest enterprise for the production of high-grade phosphate raw materials and nepheline concentrate JSC "Apatit", and to eliminate the source of its formation by developing an effective water protection measure. The investigated object is the mining and processing plant, located in the territory of the Kola Peninsula in the northern part of the country, which aggravates the existing environmental problem due to the poor stability and low self-cleaning ability of the studied ecosystems. 
Nowadays, the main source of surface waters pollution is the organized discharge of insufficiently purified mine waters in the amount of 50 million $\mathrm{m}^{3}$ per year. Therefore, in order to solve one of the main problems of the enterprise, associated with the contamination of surface waters with molybdenum, the following tasks were set:

- conducting hydro- and hydro-geochemical monitoring in the area of the mining enterprise influence;

- assessment of the level of anthropogenic pressure on water bodies;

- development of an effective method of wastewater purification from molybdenum.

\section{MATERIALS AND METHODS}

The assessment of water bodies in the impact area of the enterprise JSC "Apatit", conducted according to complex monitoring studies, showed that molybdenum is the main pollutant of surface water. The pollutant concentration in the studied water bodies reached $100 \mathrm{ppb}$, which is 100 times higher than the permissible norm. Neutral and slightly alkaline waters in the area of enterprise production facilities' location contributed to the active migration of molybdenum, the elevated contents of which form a hydrochemical pollution stream that is several kilometers long. Molybdenum enters water bodies as a part of the enterprise sewage waters; therefore, the main task at the first stage of the study was the identification of natural and technogenic sources of molybdenum inflow into discharged waters, as well as the assessment of its specific features chemical behavior in the aquatic environment.

Elevated levels of molybdenum in wastewater are atypical for the companies specializing in the apatite-nepheline ores extraction and processing. Molybdenum is not a concomitant component of mined ores and does not refer to the mandatory controlled indicators of raw material quality. Thus, a detailed study of geological information about studied area was carried out.

The fields, developed by the enterprise, are confined to the Hibiny mountain massif. The data of the Hibiny's geological map shows a belt of peculiar late-time faults - a complex of hibinites follows beyond the zone of apatite-nepheline ores. Molybdenum mineralization in the form of molybdenite is confined to this arc.

The analysis of geological data showed that molybdenite $\left(\mathrm{MoS}_{2}\right)$ is widely distributed in the
Hibiny mountain massif. At the same time, mining is accompanied by a violation of the natural state of the mountain massif, an obligate molybdenite outlet to the surface and its degradation in size. Molybdenum is leached from molybdenite in oxidizing conditions, when free oxygen is available. The main mechanisms of molybdenum leaching are oxidation, hydrolysis and alkaline dissolution. They are leading to an increase concentration of molybdenum in the waters:

$$
\begin{gathered}
\text { leaching: } \\
2 \mathrm{MoS}_{2}+9 \mathrm{O}_{2}+6 \mathrm{H}_{2} \mathrm{O}=2 \mathrm{H}_{2} \mathrm{MoO}_{4}+4 \mathrm{H}_{2} \mathrm{SO}_{4} \\
\text { hydrolysis and alkaline dissolution: } \\
\mathrm{MoS}_{2}+4 \mathrm{OH}^{-}=\mathrm{MoO}_{4}^{2-}+2 \mathrm{H}_{2} \mathrm{~S}
\end{gathered}
$$

In order to confirm the proposed assumptions, it was decided to include sampling points of mine waters from all developed horizons in the temporary expedition network. Subsequently, 30 samples of mine waters, which are a potential source of the surface waters pollution, were taken.

The quantitative chemical analysis of samples was carried out by atomic absorption method. The results showed that in all mine waters there is a multiple excess of the molybdenum maximum allowable concentration in the water used for fishery. According to the results of laboratory analysis, the molybdenum concentration in groundwater at different horizons varied over a wide range from 48 to $112 \mathrm{ppb}$. The reason for this is the variation in the content of the molybdenum soluble forms in underground water inflows due to the material composition heterogeneity of the extracted ore.

In the course of scientific and practical research it was proven that high molybdenum content in the general water use system of JSC "Apatit" is the result of a complex interaction of production and natural factors. Field developing leads to the creation of specific acid-alkaline, oxidation-reduction and hydrological conditions, which contribute to the molybdenite dissolution.

The molybdenum properties determine its increased migration ability in a large $\mathrm{Eh}-\mathrm{pH}$ range, as evidenced by the data of the Purbe diagram, with significant variations in the chemical composition of groundwater (Fig. 1).

As can be seen from Figure 1, the element exists predominantly in the form of molybdate ion $\mathrm{MoO}_{4}^{2-}$ in an oxidizing environment in the alkaline region.

In order to confirm the foregoing, laboratory conditions, a qualitative determination of the mo- 


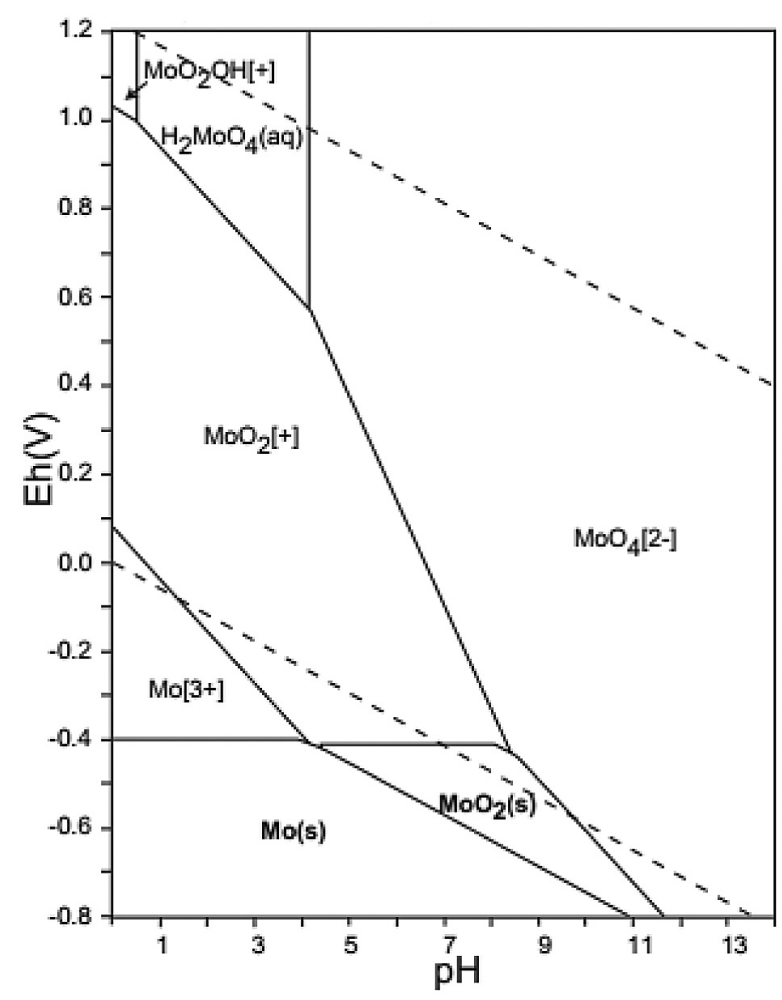

Figure 1. Diagram of the molybdenum various forms as the $\mathrm{Eh}-\mathrm{pH}$ function (the Purbe diagram).

lybdate ion in the investigated mine waters was carried out. It is based on the formation of molybdenum acid salts in the presence of $\mathrm{PO}_{4}^{2-}$ ions in acidic medium. The molybdenum acid salts colors the solution blue after the reduction with ascorbic acid. The positive result of the experiment made enabled to draw an unambiguous conclusion that molybdate ion is the predominant form of molybdenum in the investigated waters.

As the result of mine waters being discharged into natural waters, a large part of the molybdenum remains in solution, as molybdate ion $\mathrm{MoO}_{4}{ }^{2-}$ has a weak affinity for the solid surface. When molybdenum is bound to complexes with humic substances, in particular with fulvic acids, transition to a suspended state does not occur either. This is because, on the one hand, fulvic acids contributed to the metals stabilization in the dissolved state, and on the other hand, they are poorly sorbed by suspended substances.

A comprehensive assessment of water bodies state, located in the influence area of JSC "Apatit", showed that it is necessary to improve the treatment facilities in order to prevent further spread of technogenic anomalies and dysfunction of aquatic ecosystems.

The choice of the optimal sewage treatment method is determined by several factors, which include the concentration and occurrence form of a pollutant component in water, the composition, amount of wastewater, possibility and economic feasibility of extracting impurities, as well as the requirements for quality of purified water. An overview of the main methods of sewage treatment from molybdenum showed that the majority of enterprises, faced with the problem of formation of molybdenum-containing wastewater, actively used reverse osmosis and ultrafiltration, electrodialysis, and chemical methods. However, taking into account the volume of water inflow and the concentrations of molybdenum in mine waters, none of the above-mentioned methods can be implemented on the given mining enterprise, because of the high economic cost and (or) insufficient cleaning efficiency.

Currently, sorption and ion exchange purification methods are widespread. Taking into account specifics of the mining enterprises' sewage formation, consisting in the multicomponent, multitonous and irregular water inflow, these methods need a significant improvement and carrying out series of theoretical and experimental studies.

The next stage of the studies was the search for the most suitable raw material for the sorbents production, which are capable of increasing the efficiency of wastewater treatment from molybdenum. Natural mineral sorbents are most promising on the territory of the Kola Peninsula, among which clay, vermiculite and argillite were considered in this work. In the course of laboratory tests involving potential sorbents for the mine waters purification from molybdenum, the maximum efficiency of $70 \%$ was achieved by clay, activated of $0.1 \mathrm{~N}$ sulfuric acid in the ratio solid : liquid $=5: 1$. The analysis of the considered natural materials' chemical composition showed up the direct relationship between efficiency of model solutions purification from molybdenum and iron content of the test material. At the same time, the physicochemical properties of molybdenum confirm the possibility of its precipitation from solution as insoluble compounds with iron:

$$
\begin{gathered}
\mathrm{Fe}^{2+}+\mathrm{MoO}_{4}^{2-}=\mathrm{FeMoO}_{4} \downarrow \\
\mathrm{Fe}^{3+}+\mathrm{MoO}_{4}^{2-}=\mathrm{Fe}_{2}\left(\mathrm{MoO}_{4}\right)_{3} \downarrow
\end{gathered}
$$

Natural sorbents belong to exhaustible resources; however huge territories are alloscated daily for storing industrial wastes. Therefore iron wastes were collected for further research. Using the sorbents based on waste production, can not only solve the environmental problem of the en- 
terprise, but also significantly reduce the cost of the final product.

Nowadays, the wastes from the chemical industry, as well as metallurgical and metalworking production can be attributed to the waste with the required chemical composition. In order to study the sorption properties of iron-containing waste in relation to molybdenum, the slag of sulfuric acid production and metal waste represented by steel shavings were chosen. Laboratory experiments, confirmed the previously proposed assumption about the correlation between the iron content in the material and the purification efficiency, since in the case of using each of the wastes, the degree of molybdenum extraction from a model solution with a concentration of $1 \mathrm{ppb}$ reached $99 \%$. However, evaluation of the components desorption was carried out, because of the multicomponent slag composition and the high probability of potentially hazardous contaminants migration into the solution. The results of the experiment showed that a number of components, including heavy metals (zinc, copper, iron, manganese) migrated from the slag into the solution, which constituted the waste in the wastewater purification process from molybdenum.

A sample of non-alloy steel shavings was selected for further research due to the highest cleaning performance from of all the studied ironcontaining materials.

\section{RESULTS}

On the basis of the data obtained in the laboratory experiments, it was established that the main mechanism of model solutions purification from molybdenum using iron-containing metal waste is chemisorption, which proceeds with the formation of insoluble molybdates of iron and their subsequent sorption on the developed corroded of the steel shavings.

In order to intensify the process of formation of the oxide and hydroxide forms of iron with a developed specific surface and high reactivity, a part of the steel shavings portions were exposed to various activators of corrosion on the air, namely, deionized water and solutions of sulphuric acid.

Next, the portions of the treated and untreated steel shavings samples with a specific surface area of $25 \mathrm{~cm}^{2} / \mathrm{g}$ and a mass of $1 \mathrm{~g}$ were placed in model solutions with a volume of $250 \mathrm{dm}^{3}$ and a molybdenum concentration of $1 \mathrm{ppm}$ in the mix- ing mode on an orbital shaker (stirring speed 300 rpm) for 20 hours at a temperature of $18^{\circ} \mathrm{C}$ and $\mathrm{pH}=5.2$. After the cleaning process, molybdenum concentration was determined by means of atomic emission spectrometry with inductively coupled plasma. The experiment results showed that pre-treatment of steel shavings samples deionized water and sulfuric acid with concentration of $0.01 \mathrm{~N}$ leads to an increase in the efficiency of the model solution purification on $30 \%$. In the case of increasing acid concentration, the efficiency of purification decreased, and the residual iron concentration in the solution after purification was dramatically increased, due to the processes of iron passivation under the action of concentrated acids. Therefore, all subsequent experiments were performed using steel shavings samples, activated with deionized water.

Steel shavings with different values of the specific surface area $\left(30,25,15\right.$ and $\left.8 \mathrm{~cm}^{2} / \mathrm{g}\right)$, which was determined by the method of BET on a fast analyzer of specific surface and pore size, were taken to establish the dependence of the purification efficiency from the size of the iron-containing metal waste samples. The conditions of the experiment were similar to the previous one. The results of the experiment are presented in table 1 .

As can be seen from table 1, purification efficiency of model solutions from molybdenum increases along with the specific surface area of the steel shavings samples, because of the growing number of corrosion products. In turn, the rate of corrosion depends on temperature, $\mathrm{pH}$ and oxygen saturation of purification solution. Given the climatic conditions considered in the work of the enterprise, a separate series of experimental studies were devoted to the study of these parameters.

As it is known, the corrosion rate typically increases with the temperature, due to raised chemical reaction rate, diffusion rate and solubility of corrosion products protected the surface. Model solutions with a molybdenum concentration of $1 \mathrm{ppm}$ were prepared and aged in a thermostat at temperatures of $25,20,15,10$ and $5^{\circ} \mathrm{C}$ to establish the purification efficiency at various tempera-

Table 1. Efficiency of the model solutions purification from molybdenum, using steel shavings samples with different specific surface area

\begin{tabular}{|l|c|c|c|c|}
\hline $\begin{array}{l}\text { The specific surface area of } \\
\text { the steel shavings samples, } \\
\mathrm{cm}^{2} / \mathrm{g}\end{array}$ & 8 & 15 & 25 & 30 \\
\hline Efficiency of purification, \% & 23 & 37 & 51 & 58 \\
\hline
\end{tabular}


tures. Next, the processed steel shavings sample with a mass of $1 \mathrm{~g}$ and the specific surface area of $25 \mathrm{~cm}^{2} / \mathrm{g}$ was placed in a model solution with a volume of $250 \mathrm{~cm}^{3}$. The solution was mixed on an orbital shaker at $300 \mathrm{rpm}$ for 20 hours. The results of this experiment showed that the degree of molybdenum extraction increases along with the temperature due to the intensification of the process of iron oxides formation on the steel shavings surface and the insoluble iron molybdate formation. Hence, the purification efficiency was $40 \%$ at a temperature of $5^{\circ} \mathrm{C}$, and $72 \%$ at $25^{\circ} \mathrm{C}$.

The next series of experiments was devoted to study the medium $\mathrm{pH}$ value influence on the purification efficiency of molybdenum-containing model solutions with steel shavings. According to the literature sources, it was revealed that at $\mathrm{pH}>9.5$ iron is passivated in the presence of alkalis and dissolved oxygen, resulting in a decrease of the corrosion rate. At $\mathrm{pH}$ from 4 to 9.5, the rate remains constant due to corrosion with oxygen depolarization. In acidic media $(\mathrm{pH}<4)$ the corrosion rate is high due to the dissolution of iron oxide, the $\mathrm{pH}$ decreases on iron surface and the direct contact of iron with the electrolyte. The study of the medium $\mathrm{pH}$ effect on the purification process of the molybdenum model solution was carried out in the range of 3 to 9 units at a constant temperature of $18^{\circ} \mathrm{C}$.

$1 \mathrm{M}$ nitric acid solutions and sodium hydroxide was used to regulate the medium $\mathrm{pH}$. Other experimental conditions were the same as the conditions in experiment of the temperature influence. These studies showed that at $\mathrm{pH}=3$ there is a sharp increase in the efficiency of model solutions purification to $99.9 \%$. This is due to the high corrosion rate in acidic environment, which leads to the formation of iron oxides large amounts, having high reactivity and forming insoluble molybdates. The offset of the $\mathrm{pH}$ value in the alkaline region leads to a natural reduction in the cleaning efficiency related to the passivation of iron.

The corrosion rate dependence on dissolved oxygen in water was presented in Figure 2. If the oxygen plays the role of a depolarizer, the corrosion rate increases in a linear relationship (1) shown in Figure 2. If oxygen is a passivator (2), the corrosion rate increases due to the loss of metal on oxides formation, at low and medium concentrations of $\mathrm{O}_{2}$ and at large concentrations, it falls as all the metal surface is covered with a protective oxide film. It should be noted that oxygen helps to reduce the number of corrosion centers on the metal surface, which can cause corrosion process; however, it helps to increase the corrosion rate at the point that started to corrode.

In order to create anoxic environment in the experiment, the model solution in one of the bottles was degassed, using water jet vacuum pump, then purged with hydrogen with the consumption of $1 \mathrm{l} / \mathrm{min}$ during the entire contact time.

Open and closed systems were created in another two bottles. For this purpose, one of the bottles was tightly closed with plug after adding a chemical adsorbent, and the other was left open during the entire contact time. Oxygen atmosphere with a high concentration of dissolved oxygen was obtained by pumping pure oxygen with flow rate of $11 / \mathrm{min}$ during the entire contact time. Other experimental conditions were the same as in experiments in which the effect of temperature and $\mathrm{pH}$ on the efficiency of the chemical adsorbent were studied.

The efficiency of purification grows up with increasing of oxygen concentration. The maximum value of the purification efficiency $(73 \%)$ was achieved at the maximum oxygen concentration of $9 \mathrm{mg} / \mathrm{dm}^{3}$ in the model solution.

Scientific-research studies have shown that high rates of wastewater purification from molybdenum can be achieved in the case of using activated steel shavings. Activation can be achieved by pre-treatment of steel shavings portions with deionized water on the air.

The results of the conducted experiments enabled to open a new direction for the secondary using of metalworking wastes, i.e. purification of large-tonnage molybdenum-containing sewage.

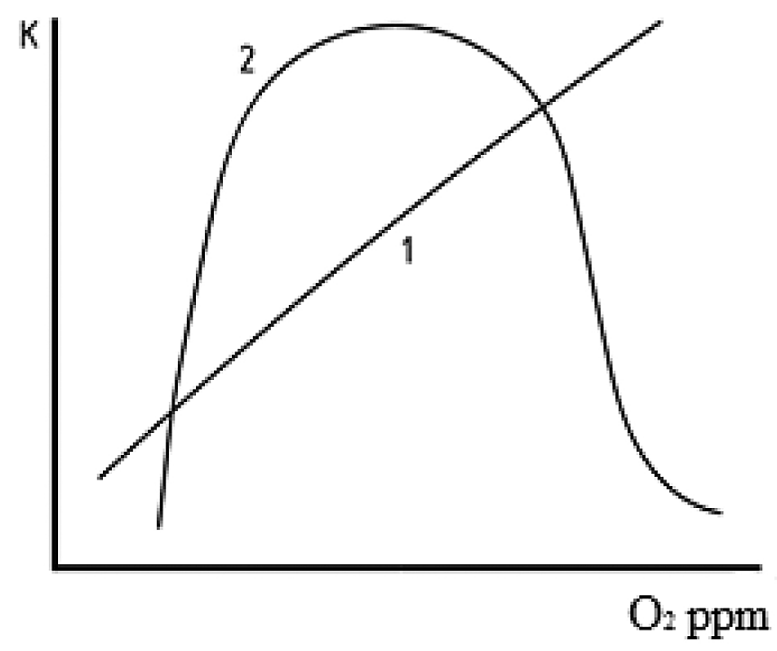

Figure 2. Dependence of iron corrosion rate in water on the concentration of dissolved oxygen: 1 - the oxygen is a depolarizer, 2 - the oxygen is a passivator 


\section{CONCLUSION}

The research consisted in the assessment and reduction of the negative impact of the largetonnage molybdenum-containing wastewater on the water objects, located in considered district through the development of an ecologically effective and economically advantageous wastewater treatment technology that allows:

- to achieve the purification efficiency of the investigated wastewater from molybdenum up to $99 \%$;

- to suggest a new direction for the secondary using of metalworking waste represented by steel shavings - the creation of a chemosorbent;

- to significantly reduce the cost of purification as a result of using metal waste as a chemisorbent, which is formed in an ample quantity in mining enterprises;

- to carry out sewage purification from molybdenum in a wide range of temperatures, $\mathrm{pH}$ and dissolved oxygen concentration in the treated waters;

- to prevent the further spread of the hydrochemical anomaly and the disruption of the aquatic ecosystem located in the considered area;

- to improve the ecological situation and the quality of the population life in the considered area.

\section{Acknowledgments}

The Common Use Centre of Mining University supported the scientific research.

\section{REFERENCES}

1. Ajeagah G.A., Foto M.S., Njine T., 2010. Application of ciliates population dynamics and physicochemical variables in the assessment of pollution in an equatorial water system. Int. J. Ecol. Dev., 15 (1), 43-53.

2. Al-Khafaji, Y., Prior, T.J., Elsegood, M.R.J., Redshaw, C., 2015. Molybdenum (VI) imido complexes derived from chelating phenols: Synthesis, characterization and $\varepsilon$-caprolactone rop capability.
Catalysts, 5 (4), 1928-1947.

3. Atlas of Eh-pH diagrams. 2005. Intercomparison of thermodynamic databases. National Institute of Advanced Industrial Science and Technology. Research Center for Deep Geological Environments. Naoto Takeno, pp. 285.

4. Busev A.I. 1962. Analytical chemistry of molybdenum. AN SSSR, Moscow, pp. 305.

5. Buzuku S., Kraslawski A., 2015, Application of morphological analysis to policy formulation for wastewater treatment. Journal of Mining Institute, 214.102-108.

6. Chukhrov F.V. 1978. Mineralogy of the Hibiny massif. Nauka, Moscow, pp. 586.

7. Krainov S.R., Ryzhenko B.B., Shvets V.M. 2004. Geochemistry of groundwater. Theoretical, applied and ecological aspects. Nauka, Moscow, pp. 677.

8. Linnik P.N., . Ignatenko I.I, 2015, Molybdenum in natural surface waters: the content and deportment. Hydrobiological journal, 51 (2), 89-113.

9. Perelman A.I. 1982. Geochemistry of natural waters. Nauka, Moscow, pp. 154.

10. Ramesh Prasad Bhatt, Sanjya Nath Khanal, 2012, A Study on Change in Flow Regime and Discharge Impacts on Water Quality of Hydropower Operation. Int. J. Ecol. Dev., 21 (1), 76-88.

11. Sakovich G.G. 2010. Determination of corrosion resistance of metals in alkaline, neutral and acidic media: methodical recommendations. Biysk, Alt. GOS. Techn. University Press, pp. 39.

12. Thiam A., Jezeque D., Groleau A. et al, 2014. Biogeochemical dynamics of molybdenum in a crater lake: seasonal impact and long-term removal. J. Water Res. Protect, 6, 256-271.

13. Voronov Y.V., Yakovlev S.V. 2006. Water disposal and sewage treatment. Moscow, ASV.

14. Wang D., Aller R.C., Sanudo-Wilhelmy S.A., 2009. A new method for the quantification of different redox-species of molybdenum ( $\mathrm{V}$ and $\mathrm{VI}$ ) in seawater. Mar. Chem., 113, 250-256.

15. Xu N., Christodoulatos C., Braida W., 2006. Adsorption of molybdate and tetrathiomolybdate onto pyrite and goethite: effect of $\mathrm{pH}$ and competitive anions. Chemosphere 62, 1726-1735.

16. Zelikman A.N. 1970. Molybdenum. Metallurgy, Moscow, pp. 441. 